\title{
Differential effects of glucose and fructose on hexose metabolism in dog spermatozoa
}

\author{
T. Rigau ${ }^{1}$, M. Rivera ${ }^{1}$, M. J. Palomo ${ }^{1}$, J. M. Fernández-Novell², \\ T. Mogas ${ }^{1}$, J. Ballester ${ }^{1}$, A. Peña ${ }^{1}$, P. J. Otaegui ${ }^{3}$, J. J. Guinovart ${ }^{2}$ \\ and J. E. Rodríguez-Gil ${ }^{1 *}$ \\ ${ }^{1}$ Unit of Animal Reproduction, Department of Animal Medicine and Surgery, and \\ ${ }^{3}$ Department of Biochemistry and Molecular Biology, School of Veterinary Medicine, \\ Autonomous University of Barcelona, E-08193 Bellaterra, Spain; and ${ }^{2}$ Department of \\ Biochemistry and Molecular Biology, University of Barcelona, E-08028 Barcelona, Spain
}

Incubation of dog spermatozoa with $10 \mathrm{mmol} \mathrm{I}^{-1}$ glucose or fructose rapidly increased the intracellular content of glucose 6-phosphate and fructose 6-phosphate, although the effect of fructose was greater. These effects were correlated with increases in ATP, ribose 5-phosphate and glycogen contents, and in the rates of formation of Llactate and $\mathrm{CO}_{2}$. In all cases, except for ATP and glycogen, the effect of fructose was greater than that of glucose. The total hexokinase activity of the crude extracts of dog spermatozoa was more sensitive to fructose than to glucose at lower concentrations $\left(0.1-3.0 \mathrm{mmol} \mathrm{I}^{-1}\right)$. Both monosaccharides induced a fast and intense increase in the overall tyrosine phosphorylation of dog spermatozoa, although their specific induced-phosphorylation patterns differed slightly. Glut 3 and Glut 5 hexose transporters were the main hexose transporters in dog spermatozoa; however, other possible SGLT family-related hexose transporters were also localized. These data indicate that, at concentrations from $1 \mathrm{mmol} \mathrm{I}^{-1}$ to $10 \mathrm{mmol} \mathrm{I}^{-1}$, fructose has a stronger effect than glucose on hexose metabolism of dog spermatozoa. These differences appear to be related to variations in the sensitivity of hexokinase activity. Moreover, the differential hexose metabolism induced by the two sugars had distinct effects on the function of dog spermatozoa, as revealed by the diverse patterns of tyrosine phosphorylation.

\section{Introduction}

Fresh mammalian spermatozoa obtain the energy necessary to maintain motility by introducing appropriate substrates into the glycolytic pathway and the Krebs cycle. It is generally accepted that monosaccharides provide the external source of substrates with which the energy status of these cells is maintained. Thus, mature mammalian spermatozoa have the ability to form lactate from several hexoses, such as glucose, fructose and mannose (Mann, 1975). Moreover, these spermatozoa can use three-carbon molecules, such as glycerol, by introducing them into the glycolytic pathway (Jones et al., 1992). However, species differ greatly in their ability to use sugars throughout the glycolytic pathway (Rikmenspoel and Caputo, 1966; Hammersted and Lardy, 1983; Jones and Connor, 2000). It is necessary to study the maintenance and regulation of the energy status of spermatozoa to understand their survival and the way by which they modulate their activity during their life cycle. Nevertheless, few studies have addressed this question.

*Correspondence

Email: juanenrique.rodriguez@uab.es
Glucose and fructose are two of the most commonly found monosaccharides in mammalian seminal plasma, although other sugars, such as sorbitol or mannose, can also be detected (Setchell and Brooks, 1988). The presence of either glucose or fructose can affect the function of mammalian spermatozoa in several ways. Glucose concentrations of about $5 \mathrm{mmol} \mathrm{I}^{-1}$ produce much higher penetration rates than do fructose or mannose in human spermatozoa (Rogers and Perreault, 1990). Moreover, glucose, but not fructose, produces a high fertility rate and capacitation-like changes in the chlortetracycline fluorescence pattern of mouse spermatozoa subjected to 'in vitro' capacitation (Fraser and Herod, 1990). This finding indicates that the changes in the sperm membrane, which are needed for penetration, are glucose-dependent (Fraser and Herod, 1990). Despite these data, the mechanisms by which glucose, but not fructose, induces these effects are not known, although they are probably related to distinct effects in the management of sperm function. There are also no reports about the role of glucose or fructose in the physiology of dog spermatozoa. In this respect, the motility patterns of dog spermatozoa incubated with either fructose or glucose differ (Rigau et al., 2001), thereby indicating that these sugars act differently on the mechanisms controlling motility. Dog spermatozoa provide a good model in which 
to study the effects of monosaccharides, as canine seminal plasma does not contain significant amounts of glucose, fructose, sorbitol or mannose (Rigau et al., 2001). Thus, freshly ejaculated dog spermatozoa have no contact with these sugars before processing. However, the precise mechanisms by which these two sugars induce these separate effects remain unclear.

The aim of this study was to determine the effects of glucose and fructose on hexose metabolism of mature dog spermatozoa and, in this way, to identify the mechanisms used by these monosaccharides to induce their differential functional effects. For this purpose, the intracellular content of some of the main markers of hexose metabolism of spermatozoa, such as glucose 6-phosphate, ribose 5phosphate, glycogen and ATP, and also the rates of formation of L-lactate and $\mathrm{CO}_{2}$, were determined. The tyrosine phosphorylation pattern of dog spermatozoa was also studied to determine whether these sugars could modify it. The study was completed with the determination of the total hexokinase activity of sperm extracts and the main membrane hexose transporters present in eukaryotic cells.

\section{Materials and Methods}

\section{Materials}

Rat anti-Glut 1, anti-Glut 2, anti-Glut 3, anti-Glut 5 and anti-SGLT-1 were from Chemicon International (Temecula, CA). Anti-mouse phosphotyrosine (PY20) was from Transduction Laboratories (Lexington, KY). [U $\left.{ }^{14} \mathrm{C}\right]$ glucose and $\left[\mathrm{U}^{14} \mathrm{C}\right]$ fructose were purchased from Amersham (Little Chalfont). Glucose and fructose were obtained from Merck (Darmstad). All other reagents were of analytical grade and were supplied by Sigma (St Louis, MO), Merck, BioRad (Hercules, CA) and EMS (Fort Washington, PA).

\section{Animals and sample collection}

Semen was obtained from 11 purebred Beagle dogs aged 2-6 years. The dogs were kept in outdoor kennels, exercised twice a day and fed a balanced diet with free access to water. Semen was collected once or twice a week, without using a female, by manual stimulation into warmed $\left(37^{\circ} \mathrm{C}\right)$ sterile glass or plastic funnels. Only the sperm-rich fraction of each ejaculate was used.

\section{Processing of semen samples}

The freshly obtained sperm-rich fraction was centrifuged immediately at $600 \mathrm{~g}$ for $10 \mathrm{~min}$ and the seminal pellet obtained for four ejaculates was pooled and resuspended immediately after centrifugation in a Krebs-Ringer-Henseleit medium ( $\mathrm{pH} 7.4$ ) at $37^{\circ} \mathrm{C}$ without any monosaccharide. The sperm suspension was centrifuged again at $500 \mathrm{~g}$ for $10 \mathrm{~min}$ and resuspended in the same medium. Finally, spermatozoa were resuspended in $5 \mathrm{ml}$ Krebs-Ringer-Henseleit medium $\left(\mathrm{pH} \mathrm{7.4)}\right.$ at $37^{\circ} \mathrm{C}$ without monosaccharides. Aliquots of the suspension were placed in open vials and incubated with continuous shaking at $37^{\circ} \mathrm{C}$ with additions of fructose or glucose to the medium. The concentrations of sperm cells in the final suspension ranged from $3.5 \times 10^{5}$ to $4.0 \times 10^{5}$ spermatozoa $\mu \mathrm{I}^{-1}$, when evaluated in either a Neubauer or Thoma haemocytometer cell chamber. Finally, aliquots were taken at the times indicated and were centrifuged at $1000 \mathrm{~g}$ for $1 \mathrm{~min}$, and supernatants and pellets were frozen immediately in liquid nitrogen. These samples were stored at $-80^{\circ} \mathrm{C}$ until analysis. In all cases, a separate $10 \mu \mathrm{l}$ aliquot was collected for analysis of the total protein content of the sample and another was collected for analysis of several cellular parameters. The supernatants were used to determine the rate of L-lactate production and the pellets were used for the other analytical procedures.

The cellular parameters determined were the percentages of viability, altered acrosomes and total motility. The first two parameters were determined by counting 200-300 spermatozoa at $\times 1000$ magnification and staining by double Trypan blue-Giemsa stain, as described by Rodríguez-Gil et al. (1994). The percentage of total motility was defined as the percentage of spermatozoa that showed a curvilinear velocity (the instantaneously recorded sequential progression along the whole trajectory of the spermatozoon) $>20 \mu \mathrm{m} \mathrm{s}^{-1}$ (see Mogas et al., 1998). A computerized analytical system was used to determine motility (sperm class analyzer; Microptic, Barcelona). A $5 \mu \mathrm{l}$ sperm sample was placed on a prewarmed $\left(37^{\circ} \mathrm{C}\right)$ siliconized microslide and covered with a $25 \mathrm{~mm}^{2}$ siliconized coverslip. Observations were made at $\times 200$ magnification on a negative phase-contrast microscope with a warmed stage $\left(37^{\circ} \mathrm{C}\right)$.

For determination of glucose 6-phosphate, fructose 6-phosphate and ATP content, frozen samples were homogenized by sonication in $300 \mu \mathrm{l}$ of $10 \%(\mathrm{v} / \mathrm{v})$ ice-cold perchloric acid. Homogenates were centrifuged at $10000 \mathrm{~g}$ for $15 \mathrm{~min}$ at $4^{\circ} \mathrm{C}$, and the supernatants were neutralized with $5 \mathrm{~mol} \mathrm{~K}_{2} \mathrm{CO}_{3} \mathrm{I}^{-1}$ before analysis.

For determination of ribose 5-phosphate content, frozen samples were homogenized by sonication in $300 \mu$ of icecold $8 \%(\mathrm{v} / \mathrm{v})$ trichloroacetic acid. Homogenates were centrifuged at $10000 \mathrm{~g}$ for $15 \mathrm{~min}$ at $4^{\circ} \mathrm{C}$. The samples were neutralized with $10 \mathrm{~mol} \mathrm{NaOH}{ }^{-1}$. A further $33 \mu \mathrm{l}$ of $10 \mathrm{~mol} \mathrm{NaOH}{ }^{-1}$ was added to the neutralized homogenates for $10 \mathrm{~min}$ at $25^{\circ} \mathrm{C}$ and, finally, $33 \mu \mathrm{l}$ of $10 \mathrm{~mol} \mathrm{HCl} \mathrm{I-1}$ was added to reach $\mathrm{pH}$ 6.5. This procedure removes traces of ketopentose phosphates that could contaminate samples. Analyses were performed on these samples.

Frozen samples were homogenized by sonication with $300 \mu \mathrm{l}$ of ice-cold $30 \%(\mathrm{w} / \mathrm{v}) \mathrm{KOH}$ and heated at $100^{\circ} \mathrm{C}$ for $15 \mathrm{~min}$. Glycogen content was determined in these extracts.

Whole, fresh sperm-rich fractions of the ejaculate were centrifuged immediately at $600 \mathrm{~g}$ for $10 \mathrm{~min}$ to determine total hexokinase activity. The seminal plasma was discarded and the resultant pellets were frozen immediately in liquid nitrogen, and stored at $-80^{\circ} \mathrm{C}$ until analysis. Total hexokinase acitvity was determined in thawed samples that had been 
homogenized by sonication in $250 \mu \mathrm{l}$ of an ice-cold buffer (pH 7.4) containing 500 mmol glycilglycine $\mathrm{I}^{-1}, 2 \mathrm{~mol} \mathrm{KCl} \mathrm{I}^{-1}$, $100 \mathrm{mmol}$ dithiothreitol $\mathrm{I}^{-1}, 300 \mathrm{iu}$ aprotinin $\mathrm{ml}^{-1}$ and $100 \mathrm{mmol}$ phenylmethylsulphonyl fluoride $\mathrm{I}^{-1}$ (homogenation buffer). Homogenized samples were centrifuged at $10000 \mathrm{~g}$ for $15 \mathrm{~min}$ at $4^{\circ} \mathrm{C}$. Hexokinase activity was measured in the resultant supernatants and in the pellets, which were washed once in $500 \mu \mathrm{l}$ of the homogenation buffer to eliminate the remaining hexokinase activity. Finally, the pellets were resuspended in $250 \mu$ l homogenation buffer.

For determination of the rate of $\mathrm{CO}_{2}$ production, pooled ejaculates were processed as above, and $500 \mu \mathrm{l}$ aliquots of the final cellular suspension in the Krebs-Ringer medium were incubated for $30 \mathrm{~min}$ at $37^{\circ} \mathrm{C}$ in stoppered vials in the presence of increasing concentrations of either $\left[\mathrm{U}^{14} \mathrm{C}\right]$ glucose or $\left[\mathrm{U}^{14} \mathrm{C}\right]$ fructose. At the end of the incubations, a piece of filter paper soaked with $200 \mu$ l phenethylamine was placed into each of the vials, avoiding direct contact with the suspension. After addition of $85 \mu \mathrm{l}$ of $10 \%(\mathrm{v} / \mathrm{v}) \mathrm{HClO}_{4}$ to the cell suspension, the vials were shaken for another 30 min, and the radioactivity in the filter papers was counted. Before addition of the radioactive material, a $10 \mu \mathrm{l}$ aliquot of the cell suspension was taken to determine total protein content.

\section{Analytical procedures}

The glucose 6-phosphate concentration was determined enzymatically as described by Michal (1984), after adaptation of the method to a Cobas Bio autoanalyser. The batch of glucose 6-phosphate dehydrogenase used for the analysis (Boehringer Mannheim, Mannheim) was tested for the absence of contaminant hexose 6-phosphate isomerase activity, which could increase glucose 6-phosphate content. Only batches of glucose 6-dehydrogenase without significant hexose 6-phosphate isomerase activity were used. After determination of glucose 6-phosphate, the reaction mixture was added to 500 iu hexose 6-phosphate isomerase $\mathrm{ml}^{-1}$ (Boehringer Mannheim) and the mixture was incubated to determine the total hexose 6-phosphate content. Fructose 6-phosphate content was obtained after subtraction of the glucose 6-phosphate content from the total values, assuming that practically all of the hexose phosphates that were not glucose 6-phosphate were fructose 6-phosphate.

The concentrations of L-lactate (Noll, 1984), ribose 5phosphate (Racker, 1984), glycogen (Ballester et al., 2000) and ATP (Lambrecht and Trantschold, 1984), and total hexokinase activity (Otaegui et al., 2000), were determined after adaptation to a Cobas Bio autoanalyser.

Total protein content of the samples was determined by the Bradford method (Bradford, 1976), using a commercial kit (Bio-Rad Laboratories, Hercules, CA).

\section{Immunological techniques}

Western blot analyses were performed on dog spermatozoa that had been homogenized by sonication in ice-cold 10 mmol Tris- $\mathrm{HCl}$ buffer $\mathrm{l}^{-1}$ (pH 7.4) containing $1 \%(\mathrm{w} / \mathrm{v})$ dodecyl sodium sulphate (SDS) and $1 \mathrm{mmol}$ $\mathrm{Na}_{2} \mathrm{VO}_{4} \mathrm{I}^{-1}$ (proportion 1:5, v/v) to avoid changes in the overall phosphorylation status of the homogenates. The samples were briefly boiled using a microwave and were centrifuged at $10000 \mathrm{~g}$ for $15 \mathrm{~min}$ at $4^{\circ} \mathrm{C}$. Western blot analysis of spermatozoa was based on SDS gel electrophoresis (Laemmli, 1970), followed by transfer to nitrocellulose (Burnett, 1981). The transferred samples were tested with the antibodies at a dilution (v/v) of 1:500 (anti Glut 3), 1:1000 (anti-Glut 5 and anti-phosphotyrosine PY20), 1:2000 (anti-SGLT-1) and 1:4000 (anti-Glut 1 and anti-Glut 2). Immunoreactive proteins were tested using peroxidase-conjugated anti-rabbit secondary antibody (Amersham) and the reaction was developed with an ECLPlus detection system (Amersham).

Human spermatozoa used as positive controls in some western blot analyses were obtained from anonymous volunteers from the Autonomous University of Barcelona. Extracts from Chinese hamster ovary $(\mathrm{CHO})$ cells and from the small intestine, kidney and muscle of rats were obtained from the laboratory of J. J. Guinovart (University of Barcelona). These extracts were also used as positive controls for some western blot analyses.

Immunocytochemistry was performed with sperm cells seeded onto gelatin-coated glass coverlips (10 mm $\times 10 \mathrm{~mm}$ ). The spermatozoa were washed with phosphate-buffered saline (PBS; $\mathrm{pH} 7.4$ ) and were fixed for $30 \mathrm{~min}$ in PBS containing $4 \%(\mathrm{w} / \mathrm{v})$ paraformaldehyde. The fixed samples were incubated with $1 \mathrm{mg} \mathrm{NaBH} \mathrm{ml}^{-1}$ to eliminate autofluorescence, and blocked in $3 \%(\mathrm{w} / \mathrm{v})$ bovine serum albumin in PBS. The spermatozoa were incubated with the antibodies (dilution 1: 500, v/v) for $2 \mathrm{~h}$ at $15-17^{\circ} \mathrm{C}$, washed with PBS and treated with a tetramethylrhodamine isothiocyanate (TRITC)-conjugated swine anti-rabbit immunoglobulin (Dako, Glostrup). Fluorescence images were obtained by a Leica TCS 4D confocal scanning laser microscope (Leica Lasertechnik, Heidelberg), adapted to an inverted Leitz DMIRBE microscope and a $\times 63$ (NA 1,4 oil) Leitz Plan-Apo Lens (Leitz; Stuttgart). The light source was an argon/krypton laser (75 mW).

\section{Statistical analyses}

When stated, putative significance of differences was calculated by either two-way ANOVA (in non-paired data) or by the Student's $t$ test (in paired results).

\section{Results}

Variations in the percentages of total motility, viability and altered acrosomes in dog spermatozoa incubated in the presence or absence of fructose and glucose

Incubation of spermatozoa in a sugar-free medium induced a progressive and slight decline in their overall function, as shown by the slight decrease in the percentages of total motility and viability and the increase in the 

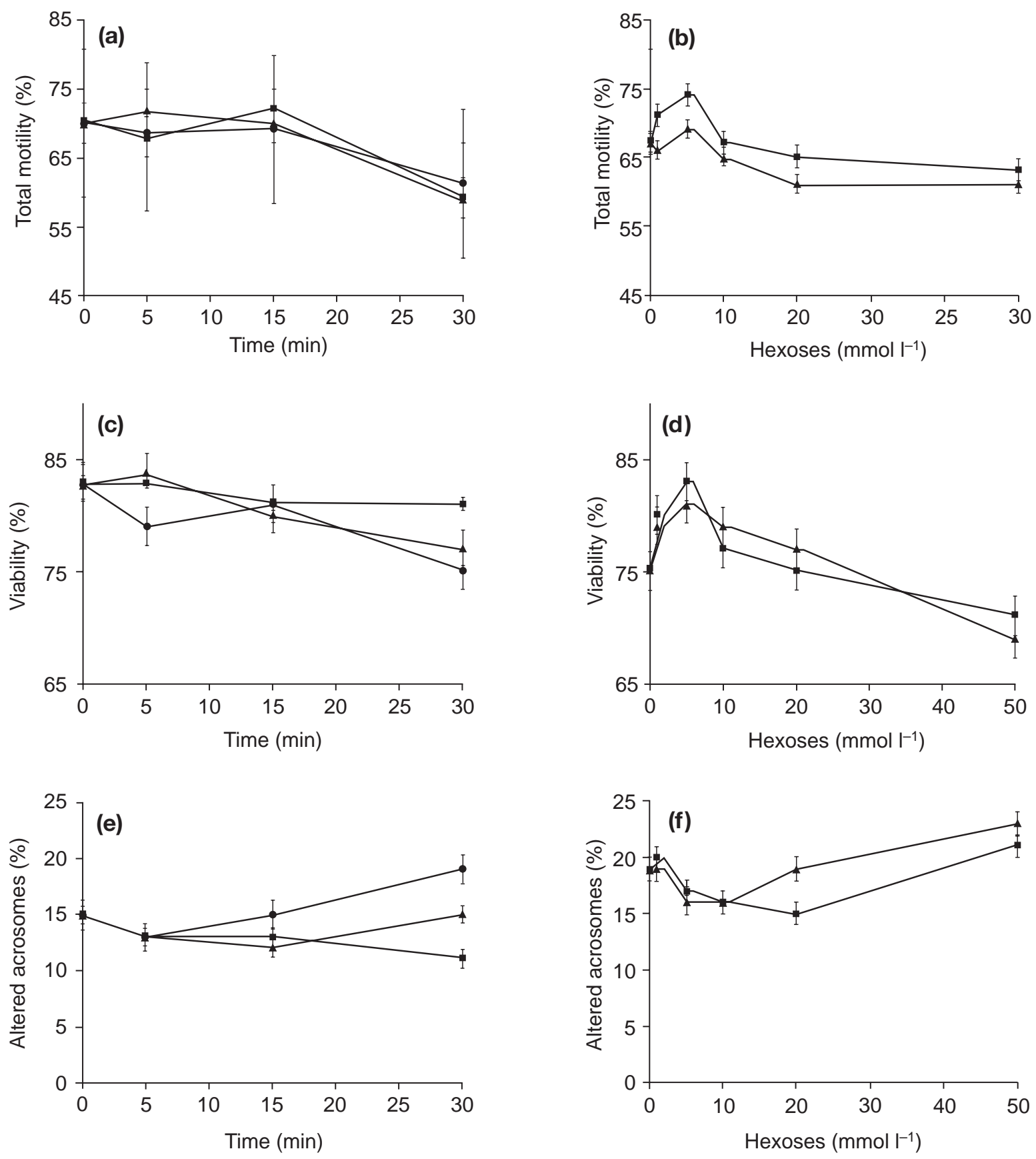

Fig. 1. Time- and concentration-dependent effects of glucose and fructose on the percentages of total motility, viability and altered acrosomes in fresh dog spermatozoa. (a,c,e) Spermatozoa were incubated in the absence ( ) or presence of $10 \mathrm{mmol}_{\text {glucose }} \mathrm{I}^{-1}(\mathbf{\Lambda})$ or $10 \mathrm{mmol}$ fructose $\mathrm{I}^{-1}(\mathbf{\square})$ and, at the times indicated, aliquots were taken to determine the percentages of (a) total motility, (c) viability and (e) altered acrosomes. (b,d,f) Spermatozoa were incubated for 15 min with increasing concentrations of glucose $(\boldsymbol{\Lambda})$ or fructose $(\boldsymbol{\square})$ and aliquots were taken to determine the percentages of $(b)$ total motility, (d) viability or (f) altered acrosomes. Data are means \pm SEM for 11 separate experiments.

percentage of altered acrosomes after 30 min of incubation (Fig. 1). The addition of either $10 \mathrm{mmol}$ glucose $\mathrm{I}^{-1}$ or $10 \mathrm{mmol}$ fructose $\mathrm{I}^{-1}$ had little effect. Only after 30 min of incubation did glucose and, partially, fructose, recover percentage viability and altered acrosomes (but not total motility), reaching values similar to those observed at the beginning of the incubations (Fig. 1). These small effects were observed at sugar concentrations from $1 \mathrm{mmol} \mathrm{I}^{-1}$ to $10 \mathrm{mmol} \mathrm{I}^{-1}$, whereas higher concentrations had a deleterious effect on spermatozoa, with a clear decrease in the percentages of 

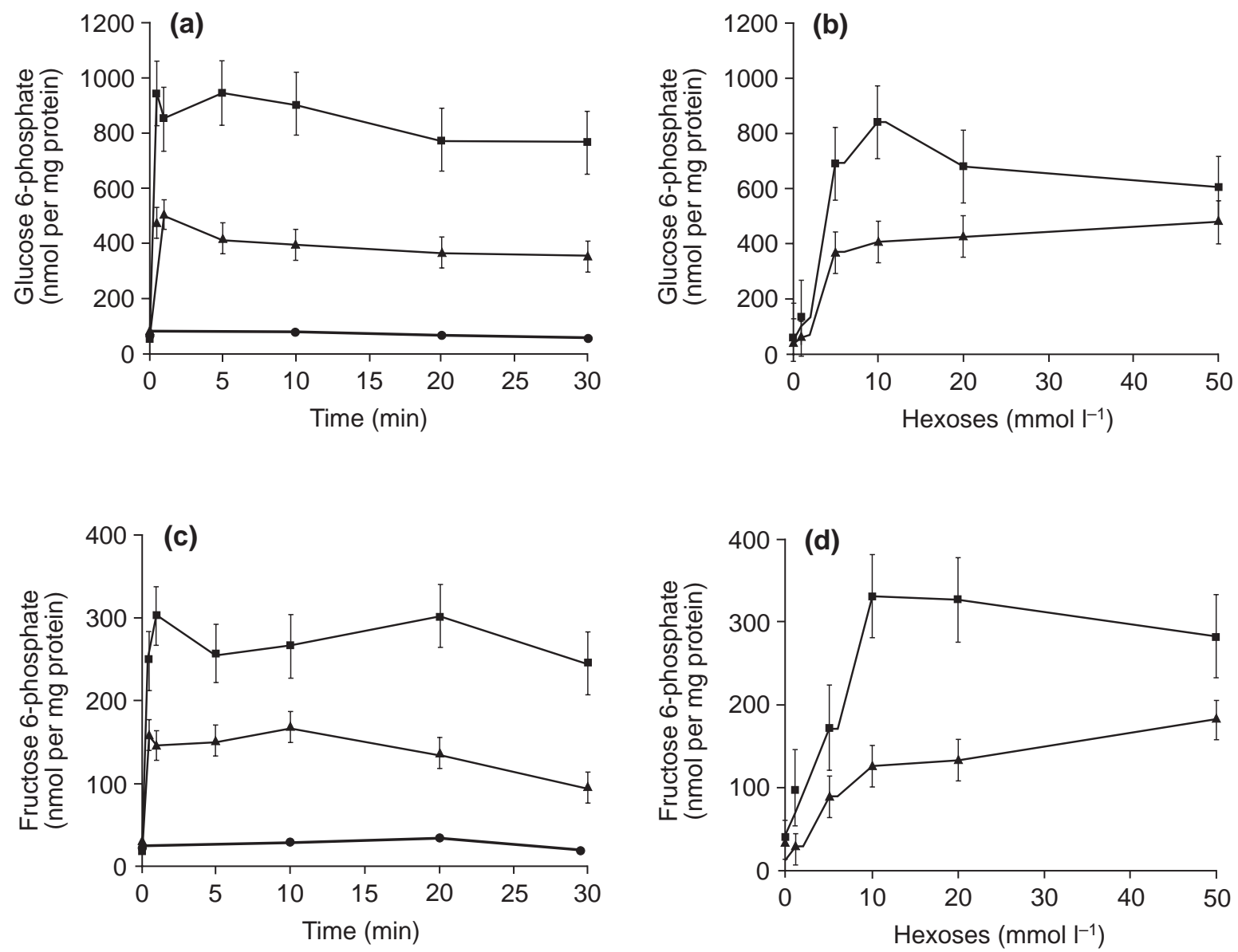

Fig. 2. Time- and concentration-dependent effects of glucose and fructose on intracellular content of glucose 6phosphate and fructose 6-phosphate in fresh dog spermatozoa. (a,c) Spermatozoa were incubated in the absence $(-)$ or

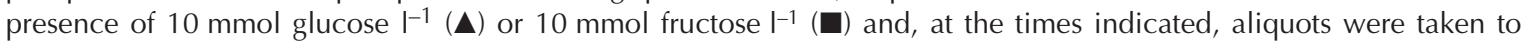
determine the intracellular concentrations of (a) glucose 6-phosphate and (c) fructose 6-phosphate. (b,d) Spermatozoa were incubated for $10 \mathrm{~min}$ with increasing concentrations of glucose $(\mathbf{\Delta})$ or fructose $(\boldsymbol{\square})$ and aliquots were taken to determine the intracellular contents of (b) glucose 6-phosphate or (d) fructose 6-phosphate. Data are means \pm SEM for 11 separate experiments.

total motility and viability, and an increase in the percentage of altered acrosomes (Fig. 1). Thus, incubation in the absence of sugars for at least $30 \mathrm{~min}$ had a slight deleterious effect on dog spermatozoa and the addition of either glucose or fructose counteracted this impairment at least partially.

Effects of glucose and fructose on intracellular content of glucose 6-phosphate and fructose 6-phosphate in dog spermatozoa from fresh ejaculates

Incubation of fresh semen with $10 \mathrm{mmol}$ glucose $\mathrm{I}^{-1}$ induced a very large, rapid and significant $(P<0.05)$ increase in intracellular glucose 6-phosphate content, which increased from about $80 \mathrm{nmol}$ per $\mathrm{mg}$ protein immediately before incubation to about $500 \mathrm{nmol}$ per $\mathrm{mg}$ protein at only $30 \mathrm{~s}$ after addition of the sugar (Fig. 2a). This increase was maintained for about $30 \mathrm{~min}$ and glucose 6- phosphate content after 30 min was about $400 \mathrm{nmol}$ per $\mathrm{mg}$ protein (Fig. 2a). The addition of $10 \mathrm{mmol}^{\text {fructose } \mathrm{I}^{-1}}$ induced an even greater increase in glucose 6-phosphate content, which increased from about $80 \mathrm{nmol}$ per mg protein to about $950 \mathrm{nmol}$ per mg protein after only $30 \mathrm{~s}$ of incubation. These values were maintained throughout incubation (about $800 \mathrm{nmol}$ per $\mathrm{mg}$ protein after $30 \mathrm{~min}$ of incubation; Fig. 2a).

The effects of these monosaccharides on glucose 6phosphate content were dose-dependent, although they differed in some aspects. The maximal effect of glucose (glucose 6-phosphate content of about $400 \mathrm{nmol}$ per mg protein) was observed at concentrations as low as $5 \mathrm{mmol} \mathrm{I}^{-1}$ (Fig. 2b). Concentrations $>5 \mathrm{mmol} \mathrm{l}^{-1}$ did not increase the effect of the sugar and doses of $1 \mathrm{mmol} \mathrm{I}^{-1}$ hardly modified glucose 6-phosphate content compared with spermatozoa incubated without sugars (Fig. 2b). In contrast, the effect of fructose increased at concentrations 

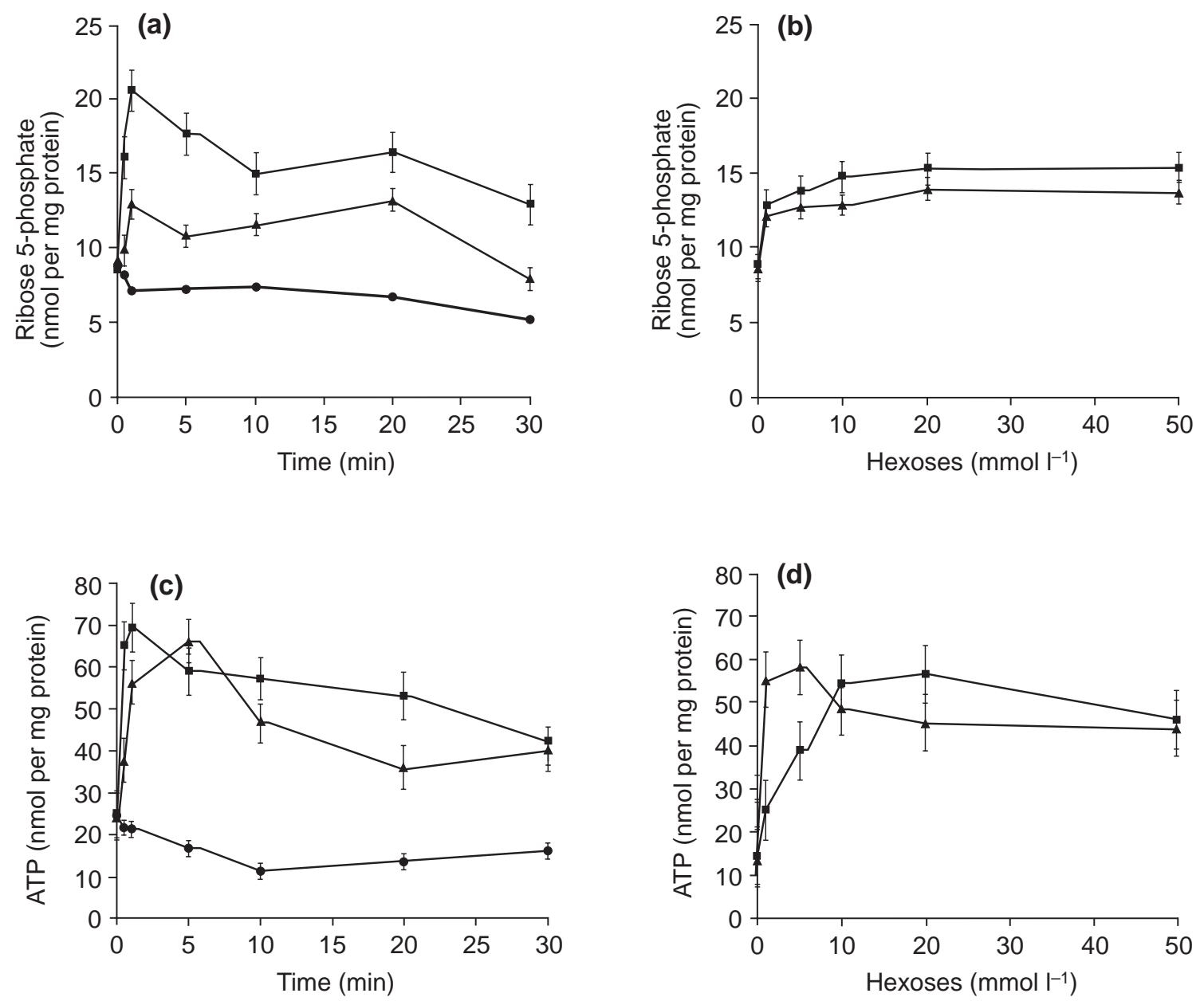

Fig. 3. Time- and concentration-dependent effects of glucose and fructose on intracellular content of ribose 5-phosphate and ATP in fresh dog spermatozoa. (a,c) Spermatozoa were incubated in the absence (-) presence of

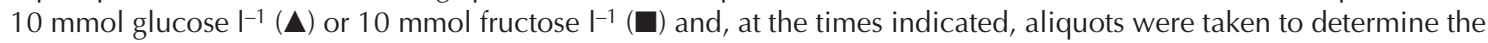
intracellular concentrations of (a) ribose 5-phosphate or (c) ATP. (b,d) Spermatozoa were incubated for 10 min with increasing concentrations of glucose $(\boldsymbol{\Lambda})$ or fructose $(\boldsymbol{\square})$ and aliquots were taken to determine the intracellular contents of (b) ribose 5-phosphate or (d) ATP. Data are means \pm SEM for 11 separate experiments.

$>1 \mathrm{mmol} \mathrm{I}^{-1}$, and peaked (glucose 6-phosphate content of about $900 \mathrm{nmol}$ per mg protein) at $10 \mathrm{mmol} \mathrm{I}^{-1}$ (Fig. 2b).

The effects of glucose and fructose on fructose 6phosphate content were also intense and rapid, and, again, fructose had a much greater and significant $(P<0.05)$ effect. Fructose 6-phosphate content increased from about $25 \mathrm{nmol}$ per mg protein in control sperm cells to about $150 \mathrm{nmol}$ per mg protein after only $30 \mathrm{~s}$ of incubation with $10 \mathrm{mmol}$ glucose $\mathrm{I}^{-1}$. These values were maintained after $30 \mathrm{~min}$ of

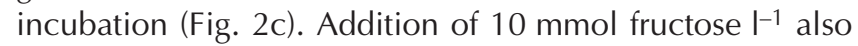
increased fructose 6-phosphate values to about $300 \mathrm{nmol}$ per mg protein after $30 \mathrm{~s}$ of incubation, which were maintained for $30 \mathrm{~min}$ (Fig. 2c).

Similar to the intracellular glucose 6-phosphate content, the effect of glucose on fructose 6-phosphate content was observed at concentrations $>1 \mathrm{mmol} \mathrm{I}^{-1}$ and reached maximal effect (about $120 \mathrm{nmol}$ per mg protein versus about $30 \mathrm{nmol}$ per mg protein in spermatozoa incubated without sugars) at doses $\geqslant 10 \mathrm{mmol}$ (Fig. $2 \mathrm{~d}$ ). Addition of fructose induced an increasing effect at doses as low as $1 \mathrm{mmol} \mathrm{I}^{-1}$, although a maximal effect (about $330 \mathrm{nmol}$ per mg protein) was obtained from $10 \mathrm{mmol} \mathrm{I}^{-1}$ upwards (Fig. 2d).

\section{Effects of glucose and fructose on intracellular ribose 5-phosphate content in dog spermatozoa from fresh ejaculates}

Dog spermatozoa from fresh ejaculates showed a ribose 5 -phosphate content of about $7 \mathrm{nmol}$ per $\mathrm{mg}$ protein. This value decreased slightly after incubation in a sugar-free medium, reaching about $5 \mathrm{nmol}$ per $\mathrm{mg}$ protein after $30 \mathrm{~min}$ (Fig. 3a). Incubation in a medium containing $10 \mathrm{mmol}$ glucose ${ }^{-1}$ induced a fast and significant $(P<0.05)$ increase 
Table 1. Time and concentration effects of glucose and fructose on intracellular glycogen content of dog spermatozoa

\begin{tabular}{|c|c|c|c|c|c|c|}
\hline \multirow[b]{2}{*}{ Treatment } & \multicolumn{4}{|c|}{ Time of incubation (min) } & & \\
\hline & 0 & 5 & 15 & 30 & & \\
\hline Without sugars & $0.24 \pm 0.02$ & $0.22 \pm 0.02$ & $0.20 \pm 0.02$ & $0.17 \pm 0.01$ & & \\
\hline $10 \mathrm{mmol}^{\text {glucose } \mathrm{I}^{-1}}$ & $0.24 \pm 0.02$ & $0.25 \pm 0.02$ & $0.27 \pm 0.02$ & $0.32 \pm 0.02$ & & \\
\hline \multirow[t]{2}{*}{$10 \mathrm{mmol}^{\text {fructose }} \mathrm{I}^{-1}$} & $0.24 \pm 0.02$ & $0.29 \pm 0.02$ & $0.39 \pm 0.02$ & $0.47 \pm 0.02$ & & \\
\hline & \multicolumn{6}{|c|}{ Hexose $\left(\mathrm{mmol} \mathrm{I}^{-1}\right)$} \\
\hline Treatment & 0 & 1 & 5 & 10 & 20 & 50 \\
\hline 30 min glucose & $0.16 \pm 0.01$ & $0.18 \pm 0.01$ & $0.22 \pm 0.02$ & $0.29 \pm 0.02$ & $0.35 \pm 0.03$ & $0.41 \pm 0.03$ \\
\hline $30 \mathrm{~min}$ fructose & $0.18 \pm 0.02$ & $0.25 \pm 0.02$ & $0.34 \pm 0.02$ & $0.41 \pm 0.02$ & $0.54 \pm 0.03$ & $0.63 \pm 0.03$ \\
\hline
\end{tabular}

Data are means \pm SEM for 11 separate experiments. Glycogen content is expressed as $\mu$ mol glucose per mg protein.

in this parameter, reaching about $12 \mathrm{nmol}$ per $\mathrm{mg}$ protein after $1 \mathrm{~min}$ (Fig. 3a), which was maintained for $20 \mathrm{~min}$, and then decreased to about $8 \mathrm{nmol}$ per $\mathrm{mg}$ protein after $30 \mathrm{~min}$ (Fig. 3a). Addition of $10 \mathrm{mmol}$ fructose $\mathrm{I}^{-1}$ induced a much greater and also significant $(P<0.05)$ increase in ribose 5 phosphate content, which reached $>20 \mathrm{nmol}$ per $\mathrm{mg}$ protein after $1 \mathrm{~min}$ and a progressive decrease, reaching about $13 \mathrm{nmol}$ per mg protein, after $60 \mathrm{~min}$ (Fig. 3a).

Increasing the concentrations of the monosaccharides in the medium did not change their effect on spermatozoa. Thus, incubation with $1 \mathrm{mmol}$ glucose $\mathrm{I}^{-1}$ for 10 min induced an increase in ribose 5-phosphate content to about $12 \mathrm{nmol}$ per mg protein (Fig. 3b). These values did not change significantly for concentrations of glucose up to $50 \mathrm{mmol} \mathrm{I}^{-1}$ (Fig. 3b). A similar effect was observed with fructose, although in this case the ribose 5-phosphate content was slightly higher (Fig. 3b).

\section{Effects of glucose and fructose on intracellular glycogen content in dog spermatozoa}

Incubation of dog spermatozoa in a sugar-free medium induced a progressive decrease in the intracellular glycogen content, which ranged from $0.24 \pm 0.02 \mu \mathrm{mol}$ glucose per $\mathrm{mg}$ protein in the initial samples (which were taken about 10 min after the washing without sugars) to $0.17 \pm 0.01$ $\mu \mathrm{mol}$ glucose per $\mathrm{mg}$ protein after $30 \mathrm{~min}$ of incubation (Table 1). Incubation with $10 \mathrm{mmol}$ glucose $\mathrm{I}^{-1}$ did not modify this parameter significantly after $15 \mathrm{~min}$ of incubation, and only after 30 min of incubation did it increase significantly $(P<0.05)(0.32 \pm 0.02 \mu \mathrm{mol}$ glucose per $\mathrm{mg}$ protein; Table 1). Incubation with $10 \mathrm{mmol}$ fructose $\mathrm{I}^{-1}$ induced a rapid and significant $(P<0.05)$ increase in glycogen content, which increased to $0.39 \pm 0.02 \mu \mathrm{mol}$ glucose per mg protein after only 15 min of incubation, and reached values of $0.47 \pm 0.02 \mu \mathrm{mol}$ glucose per $\mathrm{mg}$ protein after $30 \mathrm{~min}$ (Table 1). There was also a concentrationdependent effect of the two sugars on glycogen content, and both reached their maximal effects at concentrations of $50 \mathrm{mmol} \mathrm{I}^{-1}$ (Table 1). Notwithstanding, fructose had a much greater and more significant $(P<0.05)$ effect on glycogen $(0.63 \pm 0.03$ versus $0.41 \pm 0.03 \mu \mathrm{mol}$ glucose per $\mathrm{mg}$ protein after $30 \mathrm{~min}$ of incubation with $50 \mathrm{mmol}$ glucose $\mathrm{I}^{-1}$; Table 1 ).

\section{Effects of glucose and fructose on L-lactate production in dog spermatozoa}

Dog spermatozoa incubated in the absence of sugars did not produce significant amounts of extracellular L-lactate (Table 2). Incubation with $10 \mathrm{mmol}$ glucose $\mathrm{I}^{-1}$ induced measurable extracellular concentrations of L-lactate, which increased progressively, reaching $1.97 \pm 0.01 \mu \mathrm{mol}$ per $\mathrm{mg}$ protein after $60 \mathrm{~min}$ (Table 2). Incubation with $10 \mathrm{mmol}$ fructose $\mathrm{I}^{-1}$ induced a significant $(P<0.05)$, higher rate of $\mathrm{L}-$ lactate production, reaching $3.53 \pm 0.02 \mu \mathrm{mol}$ per $\mathrm{mg}$ protein after $30 \mathrm{~min}$ of incubation (Table 2). The greater effect of fructose was also observed when spermatozoa were incubated for $30 \mathrm{~min}$ with a concentration of monosaccharides ranging from $1 \mathrm{mmol} \mathrm{I}^{-1}$ to $50 \mathrm{mmol} \mathrm{I}^{-1}$ (Table 2).

\section{Effects of glucose and fructose on intracellular ATP content in dog spermatozoa}

Dog spermatozoa incubated in the absence of sugars showed a progressive decrease in intracellular content of ATP, which decreased from about $25 \mathrm{nmol}$ per mg protein at the start of incubation to about $15 \mathrm{nmol}$ per $\mathrm{mg}$ protein after $60 \mathrm{~min}$ (Fig. 3c). The addition of $10 \mathrm{mmol}$ glucose $\mathrm{I}^{-1}$ induced a large and rapid increase in ATP, reaching about $65 \mathrm{nmol}$ per mg protein after $5 \mathrm{~min}$, which was followed by a decrease in ATP content, reaching about $40 \mathrm{nmol}$ per $\mathrm{mg}$ protein after $30 \mathrm{~min}$ (Fig. 3c). Incubation with $10 \mathrm{mmol}$ fructose $\mathrm{I}^{-1}$ induced a faster and greater increase in ATP content, reaching about $70 \mathrm{nmol}$ per $\mathrm{mg}$ protein after $1 \mathrm{~min}$ of incubation (Fig. 3c). This increase was also followed 
Table 2. Effects of incubation with glucose or fructose on the rate of L-lactate formation in dog spermatozoa

\begin{tabular}{|c|c|c|c|c|c|c|}
\hline \multirow[b]{2}{*}{ Treatment } & \multicolumn{4}{|c|}{ Time of incubation (min) } & & \\
\hline & 0 & 5 & 15 & 30 & & \\
\hline Without sugars & $0.01 \pm 0.01$ & $0.01 \pm 0.01$ & $0.11 \pm 0.01$ & $0.27 \pm 0.01$ & & \\
\hline $10 \mathrm{mmol}^{\text {glucose }} \mathrm{I}^{-1}$ & $0.01 \pm 0.01$ & $0.24 \pm 0.01$ & $1.01 \pm 0.01$ & $1.97 \pm 0.01$ & & \\
\hline \multirow[t]{2}{*}{$10 \mathrm{mmol}^{\text {fructose } \mathrm{I}^{-1}}$} & $0.01 \pm 0.01$ & $0.49 \pm 0.01$ & $2.01 \pm 0.02$ & $3.53 \pm 0.02$ & & \\
\hline & \multicolumn{6}{|c|}{ Hexose (mmol I-1) } \\
\hline Treatment & 0 & 1 & 5 & 10 & 20 & 50 \\
\hline 30 min glucose & $0.25 \pm 0.01$ & $0.82 \pm 0.01$ & $1.01 \pm 0.01$ & $1.99 \pm 0.01$ & $2.24 \pm 0.02$ & $2.76 \pm 0.02$ \\
\hline 30 min fructose & $0.27 \pm 0.02$ & $1.14 \pm 0.01$ & $2.01 \pm 0.02$ & $3.40 \pm 0.02$ & $4.23 \pm 0.03$ & $5.15 \pm 0.03$ \\
\hline
\end{tabular}

Data are means \pm SEM for 11 separate experiments. The amount of L-lactate is expressed as $\mu$ mol per mg protein.

Table 3. Effects of glucose and fructose on the rate of $\mathrm{CO}_{2}$ production in dog spermatozoa

\begin{tabular}{lccrrr}
\hline & \multicolumn{5}{c}{ Hexose $\left(\mathrm{mmol} \mathrm{I}^{-1}\right)$} \\
\cline { 2 - 6 } Treatment & \multicolumn{1}{c}{1} & \multicolumn{1}{c}{10} & \multicolumn{1}{c}{20} & \multicolumn{1}{c}{50} \\
\hline 30 min glucose & $18.7 \pm 0.9$ & $42.8 \pm 1.9$ & $56.2 \pm 2.5$ & $90.0 \pm 3.9$ & $144.3 \pm 5.9$ \\
30 min fructose & $48.7 \pm 2.2$ & $97.5 \pm 4.5$ & $105.0 \pm 4.9$ & $120.1 \pm 5.2$ & $180.7 \pm 7.1$ \\
\hline
\end{tabular}

Data are means \pm SEM for 11 separate experiments. The $\mathrm{CO}_{2}$ production is expressed as nmol per $\mathrm{mg}$ protein.

by a progressive decrease in ATP content, reaching about $50 \mathrm{nmol}$ per mg protein after 30 min of incubation (Fig. 3c).

The effects of glucose and fructose on ATP content were concentration-dependent. The maximal effect of the former was reached at about $1-5 \mathrm{mmol} \mathrm{I}^{-1}$ of the sugar (about $55 \mathrm{nmol}$ per mg protein by incubating spermatozoa with $5 \mathrm{mmol}$ glucose $\mathrm{I}^{-1}$ for $10 \mathrm{~min}$ ). Higher concentrations of glucose induced a less intense increase in ATP content. In contrast, the maximal effect of fructose was observed at concentrations of $10-50 \mathrm{mmol} \mathrm{I}^{-1}$, with a much weaker effect than glucose at concentrations of $1-5 \mathrm{mmol} \mathrm{I}^{-1}$ (Fig. 3d).

\section{Effects of glucose and fructose on $\mathrm{CO}_{2}$ production in dog spermatozoa}

There was a clear concentration-dependent effect of both glucose and fructose on $\mathrm{CO}_{2}$ production. Thus, incubation with increasing concentrations of glucose for $30 \mathrm{~min}$ induced a progressive increase in $\mathrm{CO}_{2}$ production, with maximal production (about $180 \mathrm{nmol}$ per $\mathrm{mg}$ protein) at $50 \mathrm{mmol} \mathrm{I}^{-1}$ (Table 3). In contrast, incubation for $30 \mathrm{~min}$ with lower concentrations of fructose produced a much more intense and significant $(P<0.05)$ effect on $\mathrm{CO}_{2}$ production, reaching values of $97.5 \pm 0.06 \mathrm{nmol}$ per $\mathrm{mg}$ protein with $5 \mathrm{mmol}$ fructose $\mathrm{I}^{-1}$ compared with $42.8 \pm 0.04 \mathrm{nmol}$ per mg protein with $5 \mathrm{mmol}$ glucose $\mathrm{I}^{-1}$ (Table 3). This greater effect of fructose was maintained even at the higher concentrations used $(180.7 \pm 7.1 \mathrm{nmol}$ per $\mathrm{mg}$ protein with $50 \mathrm{mmol}_{\text {fructose }} \mathrm{I}^{-1}$ versus $144.3 \pm 5.9 \mathrm{nmol}$ per $\mathrm{mg}$

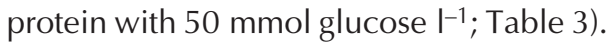

\section{Modulation of total hexokinase activity from crude dog sperm extracts by glucose and fructose}

There was a concentration-dependent effect of glucose on total hexokinase activity in both supernatants and pellet extracts from fresh dog ejaculates. Maximal activity was reached at glucose concentrations of about $3 \mathrm{mmol} \mathrm{I}^{-1}$ in both fractions (about $7 \mathrm{mU}$ per $\mathrm{mg}$ protein in supernatants and about $5 \mathrm{mU}$ per $\mathrm{mg}$ protein in resuspended pellets; Fig. $4 a, b)$. In contrast, fructose had a much more intense effect on the hexokinase activity of supernatants. In this case, the maximal effect (about $10 \mathrm{mU}$ per mg protein) was reached at concentrations as low as $0.5 \mathrm{mmol} \mathrm{I}^{-1}$, indicating a greater sensitivity for fructose (Fig. 4a). Differences in hexokinase activity between fructose and glucose were significant $(P<0.05)$. Furthermore, there was low fructose-linked hexokinase activity in pellets, only reaching detectable values at concentrations of about $3 \mathrm{mmol} \mathrm{I}^{-1}$ (Fig. 4b).

\section{Effects of glucose and fructose on the tyrosine phosphorylation pattern of dog spermatozoa}

Dog sperm extracts (total protein content by electrophoretic lane: $30 \mu \mathrm{g}$ ) from fresh ejaculates showed a faint, but well-defined, specific tyrosine phosphorylation pattern 

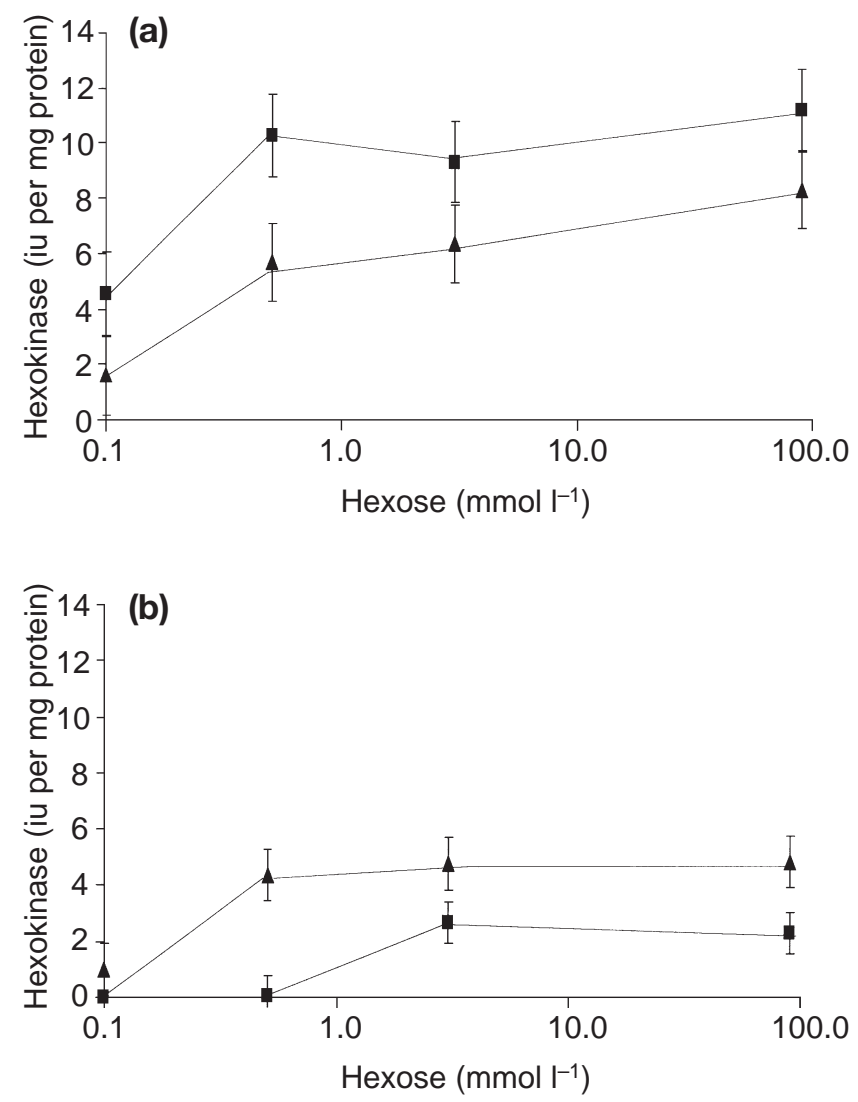

Fig. 4. Concentration-dependent effects of glucose and fructose on the total hexokinase activity of crude sperm extracts. The total hexokinase activity of (a) supernatants and (b) resuspended pellets obtained from crude extracts of fresh ejaculated dog spermatozoa was evaluated in the presence of increasing concentrations of glucose $(\boldsymbol{\Delta})$ or fructose $(\boldsymbol{\square})$. Data are means \pm SEM for 11 separate experiments.

(Fig. 5). Incubation with 2 mmol glucose $\mathrm{I}^{-1}$ induced a rapid increase in the intensity of this pattern. The increase in phosphorylation was apparent after only $30 \mathrm{~s}$ of incubation and maximal intensity was reached after $5 \mathrm{~min}$. This effect was maintained for at least $20 \mathrm{~min}$ of incubation (Fig. 5). Incubation with $10 \mathrm{mmol}$ glucose $\mathrm{I}^{-1}$ induced a similar effect (data not shown). An increase in the intensity of tyrosine phosphorylation was also observed with $2 \mathrm{mmol}$ fructose $\mathrm{I}^{-1}$. However, the fructose-induced phosphorylation pattern differed slightly from that of glucose. Thus, incubation with fructose did not induce a marked increase in the phosphorylation of a specific protein with a molecular mass of about 90 kDa (Fig. 5). Moreover, several proteins with molecular masses ranging from $85 \mathrm{kDa}$ to 125 kDa were more phosphorylated with glucose than with fructose (Fig. 5). The effect of fructose was also rapid, as it was detectable after only $30 \mathrm{~s}$ of incubation and lasted for at least $20 \mathrm{~min}$ (Fig. 5). Incubation with $10 \mathrm{mmol}$ fructose $\mathrm{I}^{-1}$ gave similar results to incubation with $2 \mathrm{mmol}$ fructose $\mathrm{I}^{-1}$ (data not shown).

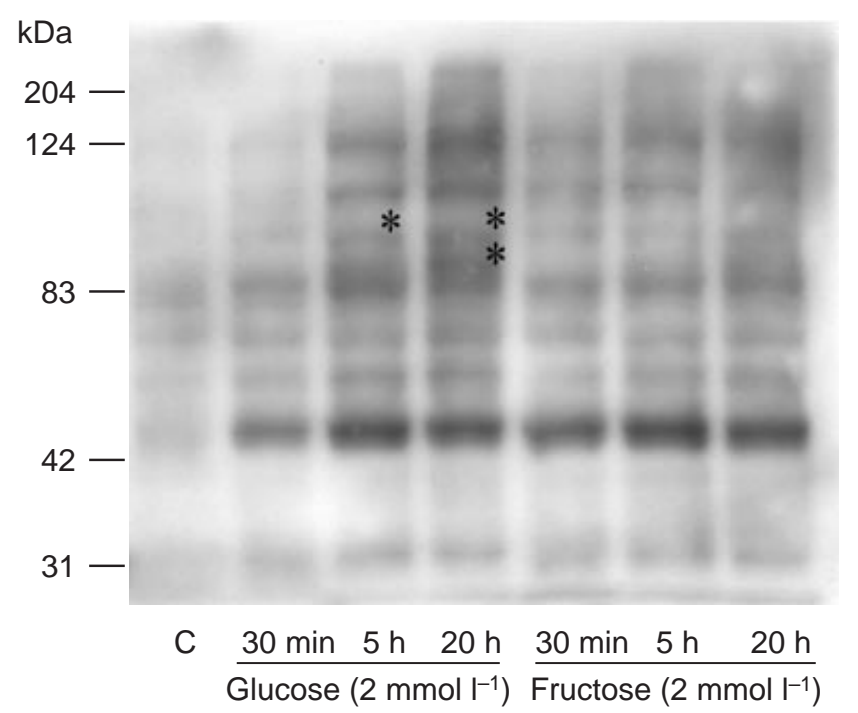

Fig. 5. Tyrosine phosphorylation pattern of pooled dog spermatozoa from four ejaculates incubated with $2 \mathrm{mmol}$ glucose $\mathrm{I}^{-1}$ or 2 mmol fructose $\mathrm{I}^{-1}$. Aliquots were collected the times indicated to determine the tyrosine phosphorylation pattern after a western blot analysis against an anti-mouse phosphorylated tyrosine antibody. The amount of total protein analysed in each lane was $30 \mu \mathrm{g}$. A representative western blot showing eight separate experiments is shown. C: samples incubated without sugars for $5 \mathrm{~min}$. Glucose $\left(2 \mathrm{mmol}^{-1}\right)$ : incubation with $2 \mathrm{mmol}$ glucose $\mathrm{I}^{-1}$. Fructose $\left(2 \mathrm{mmol} \mathrm{I}^{-1}\right)$ : incubation with $2 \mathrm{mmol}$ fructose $\mathrm{I}^{-1}$. Asterisks indicate some glucose-induced, phosphorylated proteins that were only slightly phosphorylated after fructose incubation.

\section{Expression of hexose transporters in dog spermatozoa}

Dog sperm extracts (total protein content by electrophoretic lane: $30 \mu \mathrm{g}$ ) showed several hexose transporters. Western blot analysis revealed a protein that reacted against the anti-Glut 3 antibody in spermatozoa from men and dogs (Fig. 6a). This protein has a molecular mass of about $45 \mathrm{kDa}$, which matches that observed in $\mathrm{CHO}$ cell cultures, which were used as positive controls, and is also consistent with the report of Asano et al. (1992). Our results indicate that the hexose transporter Glut 3 is present in dog spermatozoa.

In addition, the western blot analysis performed against the Glut 5 antibody showed a positive signal in dog and human spermatozoa, although in this case there were some differences. Human samples (Burant et al., 1992) had a positive signal of about $40 \mathrm{kDa}$, whereas dog sperm cells had two positive bands, at about $35 \mathrm{kDa}$ and $45 \mathrm{kDa}$. However, as Glut transporters show distinct molecular masses depending on their phosphorylation status, as well as the absence of a positive signal in the control lane of rat muscle (Fig. 6b), it can be assumed that these signals are compatible with the presence of Glut 5 in dog spermatozoa.

The analysis performed on the SGLT-1 transporter also showed two positive signals of about 50-60 kDa, which 
(a)

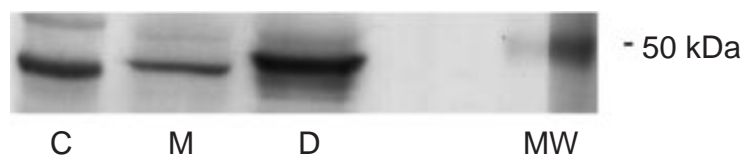

(b)

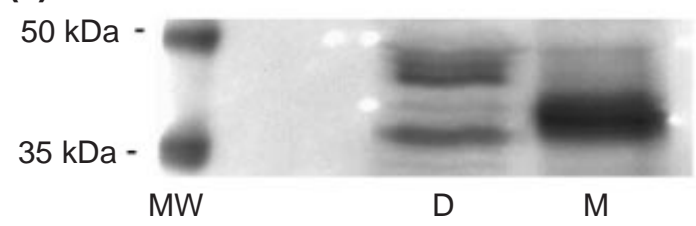

(c)

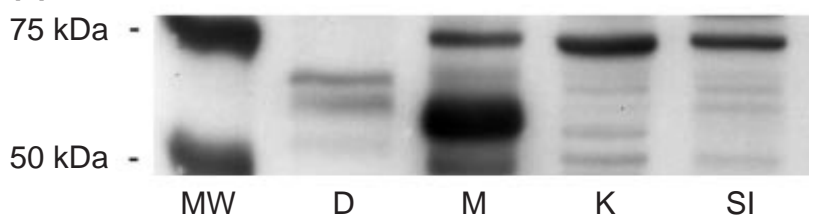

Fig. 6. Western blot analyses of hexose transporters in fresh dog spermatozoa. (a) A representative western blot using an anti-rat Glut 3 polyclonal antibody, showing the positive reaction of dog sperm (D), the two positive controls based on extracts from Chinese hamster ovary culture cells (C) and on human sperm (M). (b) A representative western blot using an anti-rat Glut 5 polyclonal antibody, showing the positive reaction of dog sperm (D), with extracts from human sperm (M) used as a positive control. (c) A representative western blot using an anti-rat SGLT-1 polyclonal antibody, showing the positive reaction of dog sperm (D); rat extracts from the small intestine $(\mathrm{SI})$, kidney $(\mathrm{K})$ and muscle $(\mathrm{M})$ were used as positive controls. MW: molecular weight markers.

may correspond to two proteins or to one protein with a distinct degree of phosphorylation glycosylation (Fig. 6c). The $50 \mathrm{kDa}$ signal was similar to that observed in extracts from rat muscle, which roughly corresponds to the low-affinity, phloretin-sensitive $\mathrm{Na}^{+} / g$ lucose cotransporter SAAT-1/SGLT2 (Mackenzie et al., 1994). Moreover, the muscle, small intestine and kidney of rat showed another band of about $75 \mathrm{kDa}$, which corresponds to the SGLT-1 transporter (Fig. 6c). As there is a close structural relationship between the proteins of the SGLT family (Mackenzie et al., 1996), recognition of all of these proteins by the same polyclonal antibody is likely, thereby indicating that the sperm proteins which recognize the SGLT-1 antibody are probably members of the SGLT family of transporters.

No positive or conclusive signals were observed when sperm extracts were tested against anti-Glut 1, anti-Glut 2 and anti-Glut 4 (data not shown).

Immunolocation of Glut 3 showed that this transporter was located mainly at the mid-piece (Fig. 7a). In contrast, Glut 5 was located mainly at the peri-acrosomal region and mid-piece (Fig. 7b), whereas the antibody against SGLT-1 showed a positive signal in the peri-acrosomal region, the equatorial zone and the mid-piece (Fig. 7c).

\section{Discussion}

The results of the present study indicate that the distinct functional effects of glucose and fructose are the result of differences in the mechanisms that maintain the equilibrium in dog sperm energy status. In this regard, the net ATP content of dog spermatozoa, which is strongly related to energy status, is the result of a dynamic equilibrium between its formation and its degradation. Our results show that fructose increases the rate of the metabolic pathways and, hence, ATP formation, more than glucose. This metabolic 'push', which is initiated by a very large and rapid increase in glucose 6-phosphate content, can be inferred by observing the effect of fructose on the rate of production of L-lactate and $\mathrm{CO}_{2}$, and on glycogen deposition. Moreover, the increase in ribose 5-phosphate content, which was even greater than that of glucose, is secondary to the increase in glucose 6-phosphate. However, fructose may increase the rate of ATP consumption in at least two ways. Firstly, by increasing the motility-related consumption of ATP. Thus, incubation with fructose results in a specific motility pattern, which is more rapid and linear than that observed after incubation with glucose (Rigau et al., 2001). As most sperm energy consumption is devoted to maintenance of motility (Roldán, 1998), the effect of fructose on motility is probably related to an increase in the rate of ATP consumption. The second mechanism of ATP consumption is related to sperm phosphorylating activity. Fructose induces a very strong increase in the rate of hexose phosphorylation with respect to glucose, as shown by the results of glucose 6-phosphate and fructose 6-phosphate. This increase, summing up the increase in the overall protein tyrosine phosphorylation, could lead to the establishment of substrate cycling, as described by Hammersted and Lardy (1983), which consumes ATP. This substrate cycling is a physiological characteristic of mammalian spermatozoa, as they rarely achieve the theoretical stoichiometric ATP yield of the glycolytic pathway (Hammersted and Lardy, 1983). Thus, the theoretical increase in ATP formation induced by incubation with fructose is counteracted by a concomitant increase in the motility-related ATP consumption and the restoration of relevant substrate cycling. The sum of these effects may explain the lack of clear differences in the net dog sperm ATP content after incubation with either glucose or fructose, although the effects of these sugars on energy status, and also on motility, differed greatly.

Despite their net, low ATP content, dog spermatozoa maintained a significant degree of motility regardless of the medium (Rigau et al., 2001). This observation indicates that these cells have a very efficient system to maintain their function. Elaborate mechanisms of modulation of metabolism, such as a functional glycogen metabolism (Ballester et al., 2000), act by optimizing the capacity of dog spermatozoa to perform their functions in an unfavourable environment by mechanisms such as maintenance of a constant intracellular ATP content over a long period of time. Therefore, longterm energy storage systems such as glycogen deposition 

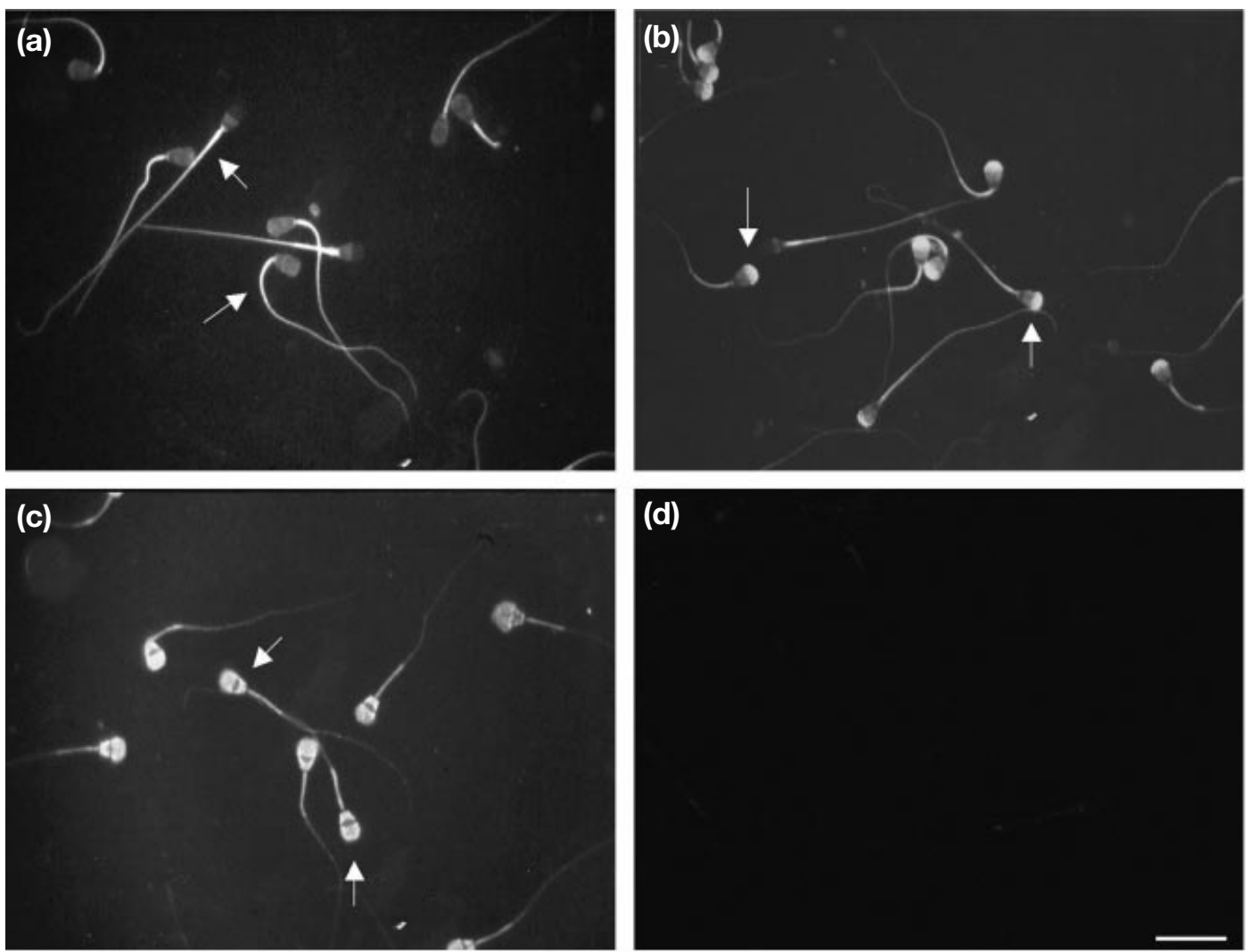

Fig. 7. Three-dimensional laser confocal images of the immunolocation of hexose transporters in fresh dog spermatozoa. Dog spermatozoa from fresh ejaculates were processed for immunocytochemical analysis in the presence of the (a) anti-Glut 3, (b) anti-Glut 5 or (c) anti-SGLT-1 antibodies, or (d) in the absence of antibodies. Arrows indicate the location of the positive signals. Scale bar represents $10 \mu \mathrm{m}$.

may form the basis of the maintenance of motility in an environment that induces very low intracellular ATP content.

Our results show that both glucose and fructose induce a rapid and strong increase in the overall protein tyrosine phosporylation of dog spermatozoa. An intriguing question remains as regards the physiological role that the sugarinduced increase in tyrosine phosphorylation has on dog spermatozoa. In mice, glucose-induced tyrosine phosphorylation is a crucial step in sperm capacitation and sperm-oocyte interaction (Visconti et al., 1995a,b; Urner et al., 2001). Similar results were not observed in dog spermatozoa in the present study. Nevertheless, an activating role for glucose and fructose on dog sperm function was observed, which is initiated by the rapid and intense increase in the tyrosine phosphorylation status of some specific proteins. This, in turn, could modulate critical sperm functions that must be modified immediately after ejaculation, namely sperm motility. Thus, the rapid changes in the motility pattern of dog spermatozoa that are induced by glucose and fructose (Rigau et al., 2001) could be related to the changes in protein phosphorylation. Moreover, the slightly different patterns of tyrosine phosphorylation observed with fructose and glucose could be reflected in differential functional effects, such as the differential motility patterns observed after incubation with glucose or fructose (Rigau et al., 2001). However, it is not surprising that incubation with sugars affects protein phosphorylation. Sugars modulate the activity of several enzymes in this way. For example, glucose and the phosphorylated metabolite glucose 6-phosphate modulate hepatic glycogen metabolism by either direct or indirect modification of the degree of phosphorylation of the key regulatory enzymes glycogen synthase and glycogen phosphorylase (Bollen et al., 1998). Thus, several effects similar to those described for glycogen metabolism could form, at least partially, the basis of the action of glucose and fructose on the tyrosine phosphorylation pattern of dog spermatozoa, which almost certainly affects the function of these cells.

Our immunological analyses indicate that there are at least two hexose transporters in dog spermatozoa, namely Glut 3 and Glut 5. Moreover, the results against the SGLT-1 antibody indicate that dog spermatozoa have at least one protein that, although it is not SGLT-1, is included in the SGLT family of $\mathrm{Na}^{+} /$voltage-dependent, phloretin-sensitive hexose and amino acid transporters. This observation can 
be inferred by the presence of a protein that is reactive to the SGLT-1 antibody with a molecular mass similar to that of the SAAT-1/SGLT-2 antibody-sensitive protein from rat muscle (Mackenzie et al., 1996). The crossreactivity of the proteins pertaining to the SGLT family to the polyclonal SGLT-1 antibody is due to the high sequence homology among these proteins, reaching values of about $90 \%$ (Mackenzie et al., 1996).

Regarding the presence of Glut 3 and Glut 5 transporters in dog spermatozoa, our results are consistent with those reported for species such as bulls, mice and humans (Burant et al., 1992; Angulo et al., 1998). However, Glut 1, Glut 2 and Glut 4 transporters were not detected in dog spermatozoa and we can only speculate about the possible role of the SGLT-family proteins as hexose transporters. Therefore, we hypothesize that the main hexose transporters of dog spermatozoa are Glut 3 and Glut 5. The variety of transporters present in dog spermatozoa shows that these cells have a complex system for optimization of hexose transport and phosphorylation. In this regard, whereas Glut 3 is a very high affinity glucose transporter, Glut 5 shows a very high affinity for fructose (Mueckler, 1990). Thus, the presence of these two hexose transporters may indicate separate uptake pathways for glucose and fructose. These separate pathways may mark the starting point that leads to the differentiated functional effects of these sugars. Moreover, the observation of a differentiated hexose sensitivity of hexokinase activity in the supernatants and pellets of the dog sperm extracts indicates a follow-up in the differentiated pathways for fructose and glucose metabolism, which would be initiated at the sugar uptake step. Thus, it is hypothesized that the differential effects of these two monosaccharides on dog sperm function are initiated by a differentiated initial pathway of sugar uptake and, perhaps, phosphorylation. Moreover, the differentiated metabolic pathways for fructose and glucose lead to questions about the physiological role of fructose in dog spermatozoa. In many mammals, spermatozoa use glucose in preference to fructose when both substrates are available (Rikmenspoel and Caputo, 1966; Bedford and Hoskins, 1990; Jones and Connor, 2000). This may indicate that fructose has no relevant role in controlling the energy status of mammalian spermatozoa, as it is not the most efficient energy substrate for these cells. However, the presence of specific machinery for metabolizing fructose shows that this sugar is indeed playing such a role. At present we can only make speculations about this, although our results indicate that this substrate plays an activating and modulating role on dog sperm function more than a role as a mere passive energy substrate. Thus, the very fast and strong metabolic reaction that dog spermatozoa undergo after fructose incubation is compatible with a functional activation of the cells, which is mainly shown in the specific motility pattern obtained (Rigau et al., 2001). This pattern differs greatly from that obtained after glucose incubation, which is less rapid and less linear (Rigau et al., 2001). Other results, such as the presence of Glut 5, but not Glut 3, in the sperm head reinforce a specific, separate role for fructose. Similar results have been reported for other species (Angulo et al., 1998). A separate location for glucose and fructose uptake could indicate a certain directionality of hexose metabolism. Thus, the presence of Glut 5 transporters in the peri-acrosomal region may indicate that the uptake of fructose by the head is needed but the reason remains unknown. In this respect, it is interesting to note that some ATP consumption occurs in the sperm head. Thus, the acrosome reaction is related to a cascade of phosphorylation-dephosphorylation reaction, which results in a net consumption of ATP (Roldán, 1998). In this sense, we cannot eliminate the possibility of the presence of a minor, semi-autonomous fructose-related, energy metabolism linked to the sperm head that may produce energy for local requirements.

In conclusion, these results indicate that the differences observed in the glucose and fructose metabolism of fresh dog spermatozoa could be mainly attributable to the differences in the phosphorylation rates of these sugars at concentrations of about $1-20 \mathrm{mmol} \mathrm{I}^{-1}$. Due consideration must be given to this point when evaluating the changes in dog sperm function during their lifetime. Moreover, a full understanding of these differentiated functional effects is necessary when designing specific extenders to conserve dog spermatozoa in refrigeration for a long period of time.

The authors would like to thank Tania Yates for her valuable assistance in preparing the English version of the manuscript. J. Boan Ballester was a recipient of a fellowship from the Generalitat de Catalunya, Spain. This work was supported partially by grant number 97/2040 from the Fondo de Investigaciones Sanitarias de la Seguridad Social, Spain.

\section{References}

Angulo C, Rauch MC, Droppelmann A, Reyes AM, Slebe JC, DelgadoLópez F, Guaiquil VH, Vera JC and Concha IL (1998) Hexose transporter expression and function in mammalian spermatozoa: cellular localization and transport of hexoses and vitamin C Journal of Cellular Biochemistry 71 189-203

Asano T, Katagiri H, Takata K et al. (1992) Characterization of Glut3 protein expressed in Chinese hamster ovary cells Biochemical Journal 288 189-193

Ballester J, Fernández-Novell JM, Rutllant J et al. (2000) Evidence for a functional glycogen metabolism in mature mammalian spermatozoa Molecular Reproduction and Development 56 207-219

Bedford JM and Hoskins DD (1990) The mammalian spermatozoon: morphology, biochemistry and physiology. In Marshall's Physiology of Reproduction pp 379-568 Ed. GE Lamming. Churchill Livingstone, Edinburgh

Bollen M, Keppens S and Stalmans W (1998) Specific features of glycogen metabolism in the liver Biochemical Journal 336 19-31

Bradford MM (1976) A rapid and sensitive method for the quantitation of microgram quantities of protein utilizing the principle of protein-dye binding Analytical Biochemistry 72 248-254

Burant CF, Takeda J, Brot-Laroche E, Bell GI and Davidson NO (1992) Fructose transporter in human spermatozoa and small intestine is Glut 5 Journal of Biological Chemistry 267 14 523-14 526

Burnett WN (1981) Western blotting: electrophoretic transfer of proteins from sodium dodecyl sulfate-polyacrylamide gels to unmodified nitrocellulose 
and radiographic detection with antibody and radioiodinated proteins Journal of Analytical Biochemistry 112 195-203

Fraser LR and Herod JE (1990) Expression of capacitation-dependent changes in chlortetracycline fluorescence patterns in mouse spermatozoa requires a suitable glycosylable substrate Journal of Reproduction and Fertility 88 611-621

Hammersted RH and Lardy HA (1983) The effects of substrate cycling on the ATP yield of sperm glycolysis Journal of Biological Chemistry 258 8759-8768

Jones AR and Connor DE (2000) Fructose metabolism by mature boar spermatozoa Reproduction, Fertility and Development 12 355-359

Jones AR, Chantrill LA and Cokinakis A (1992) Metabolism of glycerol by mature boar spermatozoa Journal of Reproduction and Fertility 94 129-134

Laemmli UK (1970) Cleavage of structural proteins during the assembly of the head of bacteriophage T4 Nature 227 680-685

Lambrecht M and Transtschold D (1984) ATP determination with hexokinase and glucose-6-phosphate dehydrogenase. In Methods of Enzymatic Analysis pp 543-551 Ed. HU Bergmeyer. Verlag Chemie, Weinheim

Mackenzie B, Panayotova-Heiermann M, Loo DDF, Lever JE and Wright EM (1994) SAAT1 is a low affinity $\mathrm{Na}^{+} / g$ lucose cotransporter and not an amino acid transporter. A reinterpretation Journal of Biological Chemistry 26922 488-22 491

Mackenzie B, Loo DDF, Panayotova-Heiermann M and Wright EM (1996) Biophysical characteristics of the pig kidney $\mathrm{Na}^{+} /$glucose cotransporter SGLT2 reveal a common mechanism for SGLT1 and SGLT2 Journal of Biological Chemistry 27132 678-32 683

Mann T (1975) Biochemistry of semen. In Handbook of Physiology pp 321-347 Eds RO Greep and EB Astwood. American Physiology Society, Washington DC

Michal G (1984) Glucose 6-phosphate. In Methods of Enzymatic Analysis pp 191-197 Ed. HU Bergmeyer. Verlag Chemie, Weinheim

Mogas T, Rigau T, Piedrafita J, Bonet S and Rodríguez-Gil JE (1998) Effect of column filtration upon the quality parameters of fresh dog semen Theriogenology 50 1171-1189

Mueckler M (1990) Facilitative glucose transporters European Journal of Biochemistry 219 713-725

Noll F (1984) L-lactate. In Methods of Enzymatic Analysis pp 582-588 Ed. HU Bergmeyer. Verlag Chemie, Weinheim

Otaegui PJ, Ferré T, Pujol A, Riu E, Jiménez R and Bosch F (2000) Expression of glucokinase in skeletal muscle: a new approach to counteract diabetic hyperglycemia Human Gene Therapy 11 1543-1552

Racker E (1984) Ribose 5-phosphate. In Methods of Enzymatic Analysis pp 399-407 Ed. HU Bergmeyer. Verlag Chemie, Weinheim

Rigau T, Farré M, Ballester J, Mogas T, Peña A and Rodríguez-Gil JE (2001) Effects of glucose and fructose on motility patterns of dog spermatozoa from fresh ejaculates Theriogenology $\mathbf{5 6} 801-815$

Rikmenspoel R and Caputo R (1966) The Michaelis-Menten constant for fructose and glucose of hexokinase in bull spermatozoa Journal of Reproduction and Fertility 12 437-444

Rodríguez-Gil JE, Montserrat A and Rigau T (1994) Effects of hypoosmotic incubation on acrosome and tail structure on canine spermatozoa Theriogenology 42 815-829

Rogers BJ and Perreault SD (1990) Importance of glycosylable substrates for in vitro capacitation of human spermatozoa Biology of Reproduction 43 1064-1069

Roldán ERS (1998) Signal transduction during mammalian sperm acrosomal exocytosis. In Gametes: Development and Function pp 219-228 Eds A Lauria, F Gandolfi, G Enne and L Gianaroli. Serono Symposia, Rome

Setchell BP and Brooks DE (1988) Anatomy, vasculature, innervation and fluids of the male reproductive tract. In Physiology of Reproduction pp 797-836 Eds E Knobil and JD Neill. Raven Press, New York

Urner F, Leppens-Luisier G and Sakkas D (2001) Protein tyrosine phosphorylation in sperm during gamete interaction in the mouse: the influence of glucose Biology of Reproduction 64 1350-1357

Visconti PE, Bailey JL, Moore GD, Pan D, Olds-Clarke P and Kopfs GS (1995a) Capacitation of mouse spermatozoa. I: Correlation between the capacitation state and protein tyrosine phosphorylation Development 121 1129-1137

Visconti PE, Moore GD, Bailey JL, Leclerc P, Connors SA, Pan D, OldsClarke P and Kopfs GS (1995b) Capacitation of mouse spermatozoa. II: Protein tyrosine phosphorylation and capacitation are regulated by a cAMP-dependent pathway Development 121 1139-1150

Received 2 August 2001

First decision 12 October 2001

Accepted 11 December 2001. 